\title{
A proteção social para pessoas com deficiência no Distrito Federal: contradições na garantia e efetivação de direitos
}

\author{
Social welfare for people with disabilities in Distrito Federal: contradictions in the guarantee \\ and enforcement of rights
}

\author{
Thaís Kristosch Imperatori* \\ Angela Vieira Neves**
}

Resumo: O presente artigo busca mostrar as contradições entre o marco legal existente e a realidade das pessoas com deficiência no Distrito Federal (DF). É realizado um resgate histórico da proteção social para pessoas com deficiência no DF, estruturada por meio de ações isoladas nas décadas de 1980 e 1990. Nos anos 2000 se busca uma proteção social em sentido ampliado pelas Leis 3.939/2007 e 4.317/2009 e pelo Plano Viver sem Limites. A metodologia contou com pesquisa documental em leis, decretos e outros atos normativos e entrevistas com diretores e lideranças de 26 entidades da sociedade civil. Os dados da pesquisa mostram a contradição entre o legal e o real a partir de três efeitos políticos: a falta de vontade política do governo, a descontinuidade das ações e a falta de recursos. Os resultados apontam para a necessidade de uma mudança na cultura política orientada pelo reconhecimento das pessoas com deficiência enquanto sujeitos de direito.

Palavras-chave: Proteção social. Deficiência. Acessibilidade. Direitos. Cultura política.

\begin{abstract}
This article seeks to show the contradictions between the existing legal framework and the reality of people with disabilities in the Federal District (Brazil). Research on the social protection history for people with disabilities in the Federal District was carried out through isolated actions in the 1980s and 1990s. In the 2000s, social protection was sought in the sense extended by Laws $3.939 / 2007$ and $4.317 / 2009$ and Plan to Live Without Limits. The methodology included documentary research on laws, decrees and other normative acts and interviews with directors and leaders of 26 civil society entities. The research data shows the contradiction between the legal text and the reality from three political points: lack of political will of the government, discontinuity of actions and lack of resources. There is a need for change in the political culture guided by the recognition of people with disabilities as subjects of rights.
\end{abstract}

Keywords: Social welfare. Disability. Accessibility. Rights. Political culture

\footnotetext{
* Graduada em Serviço Social e Ciências. Doutora em Política Social pela Universidade de Brasília (UnB). É professora do Departamento de Serviço Social da UnB e pesquisadora do Grupo de Estudos e Pesquisas sobre Democracia, Sociedade Civil e Serviço Social.

${ }^{* *}$ Assistente Social. Doutora em Ciências Sociais pela Universidade Estadual de Campinas (UNICAMP). Professora aposentada da Universidade de Brasília, vinculada como Pesquisadora e Professora ao Programa de PósGraduação em Política Social (PPGPS/UNB). Líder do Grupo de Estudos e Pesquisas sobre Democracia, Sociedade Civil e Serviço Social (GEPEDSS).
} 


\section{Considerações iniciais}

Apesar da existência de garantias legais, a precariedade das políticas públicas em diversas áreas revela uma das contradições no campo da proteção social. Nos termos de Guerra (2009), há um paradoxo entre a igualdade formal no campo jurídico e a desigualdade real no campo socioeconômico, qual seja, a fratura entre o real e o legal. Isso não significa negar a dimensão legal. Ao contrário, o reconhecimento e a afirmação de direitos são uma estratégia contemporânea e necessária, frente à sua conversão em objetos da solidariedade individual e privada, ou de consumo a ser adquirido no mercado.

Entende-se que a institucionalização de leis e normas é a base para o Estado de direito: aquele que garante direitos fundamentais orientados por um regime legal de garantias constitucionais e, no qual, os indivíduos tornam-se cidadãos. O Estado de direito, ao ter por fundamento a participação da população nas decisões sobre as políticas públicas, torna-se também democrático (SIMÕES, 2008).

A construção de um Estado de direito democrático, porém, vai além da sua definição no aparato jurídico-político, sendo imprescindível considerar a presença de elementos autoritários ou democráticos nas práticas políticas. Segundo Vieira (2004), a instalação desses Estados em sociedades com práticas pouco democráticas coloca em risco a garantia de direitos. Em outras palavras, "só a sociedade democrática tem condições de proteger e de conservar o Estado de Direito" (SIMÕES, 2008, p. 135).

Destaca-se, entretanto, que a existência de uma grande quantidade de leis e marcos normativos não assegura a construção de um espaço público com práticas políticas regidas pela noção de direitos e nem sua garantia aos cidadãos. Tampouco implica em redução de desigualdades e melhores condições de vida para a população, uma vez que "para além das garantias formais, os direitos estruturam uma linguagem pública que baliza os critérios pelos quais os dramas da existência são problematizados e julgados nas suas exigências de equidade e justiça" (TELLES, 1994, p. 92). Na mesma direção, Gueiros (1991, p. 54) argumenta que "de fato, estatuto legal não é garantia de exercício de direito. Nem sempre as forças que bastam para a inclusão do direito ao nível do jurídico são suficientes para forçar a sua efetivação".

Além disso, os traços autoritários e conservadores da cultura política brasileira não são rompidos apenas com a institucionalização de leis. Ao contrário, conforme explica Chauí, 
(...) as leis sempre foram armas para preservar privilégios e o melhor instrumento para a repressão e a opressão, jamais definindo direitos e deveres. No caso das camadas populares, os direitos são sempre apresentados como concessão e outorga feitas pelo Estado, dependendo da vontade pessoal ou do arbítrio do governante. (CHAUÍ, 1994, p. 54)

Em síntese, "as leis sempre foram consideradas inúteis, inócuas, feitas para serem violadas, jamais transformadas ou contestadas" (GUEIROS, 1991, p. 54). Conforme explica Guerra (2009, p. 47), a cultura antidemocrática da política brasileira, associada à ausência de bases institucionais democráticas, se constitui em um real impedimento para a efetivação de direitos sociais.

O presente artigo busca apresentar reflexões sobre tais contradições tendo como referência a realidade das pessoas com deficiência no Distrito Federal e o marco legal existente. Os dados apresentados no presente artigo são um recorte da pesquisa: Entre $o$ direito e a filantropia: a proteção social para pessoas com deficiência no Distrito Federal, realizada entre 2016 e 2017.

\section{Metodologia}

O percurso metodológico da pesquisa iniciou-se por meio do mapeamento de leis, decretos, portarias e demais atos normativos que versam sobre os direitos das pessoas com deficiência no Distrito Federal (DF), realizado por meio do Sistema Integrado de Normas Jurídicas do Distrito Federal (SINJ-DF). O objetivo da análise foi compreender a trajetória da proteção social para pessoas com deficiência no DF no âmbito jurídico-legal.

No período entre os anos de 1981 (quando foi identificado o primeiro registro) e 2017, foram localizados 383 atos legais e normativos, os quais foram analisados a partir dos seguintes eixos: acessibilidade; assistência social; educação e cultura; esporte e lazer; gestão pública; habitação; participação social; saúde; trabalho e emprego; transporte; e outros. Foram excluídas da análise legislações que tratam do orçamento para políticas para pessoas com deficiência, e aquelas que tratam da isenção de impostos como, por exemplo, o Imposto sobre a Propriedade de Veículos Automotores (IPVA) e o Imposto sobre Operações relativas à Circulação de Mercadorias e sobre Prestações de Serviços de Transporte Interestadual e Intermunicipal e de Comunicação (ICMS), que tratam sobre a aquisição de veículos adaptados.

Complementar a esse estudo, entre novembro de 2016 e agosto de 2017 foram realizadas entrevistas com diretores e lideranças de 26 entidades da sociedade civil atuantes 
na proteção social para pessoas com deficiência no DF, totalizando 36 participantes da pesquisa. A escolha das entidades participantes da pesquisa ocorreu a partir de critérios qualitativos. Um dos blocos de perguntas das entrevistas buscou confrontar a opinião dos entrevistados sobre o marco legal e normativo existente e sua efetivação, abordada a partir das experiências vividas na garantia de direitos e no acesso a políticas e serviços públicas no campo da proteção social.

As entrevistas foram transcritas pela entrevistadora, de modo a garantir a fidedignidade dos dados. Buscou-se preservar a sua integridade, com a revisão gramatical e organização que permita maior compreensão por parte do leitor. Entende-se que essa estratégia está compatível com o objetivo do estudo quanto ao conteúdo factual do que foi dito (GIBBS, 2009), assim como a estratégia de análise de conteúdo dos dados. A apresentação dos dados neste artigo preservará o anonimato dos entrevistados.

\section{O mosaico da proteção social no campo legal}

A primeira norma direcionada para pessoas com deficiência no DF data de 1981. Trata-se do Decreto Distrital no 5.839/1981, que instituiu uma comissão formada por representantes de diversos órgãos para planejar e coordenar os programas relativos ao Ano Internacional das Pessoas Deficientes. Esse ano foi proclamado pela Organização das Nações Unidas e gerou um amplo movimento de mobilização das pessoas com deficiência no Brasil (FIGUEIRA, 2008).

Entretanto, apenas em 1988 o então governador José Aparecido de Oliveira assinou o Decreto no 11.107/1988, que dispõe sobre as ações da Administração do DF relativas às pessoas com deficiência. Esse decreto teve como ponto de partida a criação da Coordenadoria Nacional para Integração da Pessoa Portadora de Deficiência (CORDE) pelo governo federal em 1986, que trouxe uma mudança na forma como o Estado brasileiro passou a tratar a área da deficiência, de maneira integrada e permitindo o diálogo com movimentos sociais. 0 propósito do governo local foi assegurar aos portadores de deficiência ${ }^{1}$ o pleno exercício de seus direitos básicos e a efetiva integração social. Dentre as ações destinadas às pessoas com

\footnotetext{
${ }^{1} \mathrm{Na}$ época, o termo "pessoa portadora de deficiência" era considerado o mais adequado para se referir a este público e foi utilizado em diversas normativas, inclusive no âmbito federal. Neste artigo, exceto quando se trata de textos legais citados diretamente, utiliza-se o termo "pessoa com deficiência", em consonância com a Convenção Internacional dos Direitos das Pessoas com Deficiência.
} 
deficiência estão: educação especial e gratuita; assistência, reabilitação e reinserção na vida econômica e social; acesso ao trabalho; e possibilidade de acesso a edifícios e logradouros públicos. Tais ações seriam executadas sob coordenação única do Gabinete Civil do Governador, integrando diferentes áreas.

O referido Decreto também criou um Conselho Consultivo, composto por representantes do governo e de entidades representativas de pessoas com deficiência, que tinha como atribuição participar da formulação de planos e programas que envolvam pessoas com deficiência e também realizar a aferição das ações executadas. Ainda caberia ao Conselho estabelecer prazos para a elaboração de programas setoriais destinados ao atendimento das pessoas com deficiência; cobrar o cumprimento dos prazos fixados; e representar ao governador sobre falhas e omissões detectadas na elaboração do Decreto. Esta foi a primeira experiência participativa entre governo e entidades da sociedade civil, na elaboração de uma política na área da deficiência, até então inexistente.

Assim, desde o final da década de 1980:

Art. $1^{\circ}-$ Os órgãos e entidades que compõem a Administração Pública do Distrito Federal, deverão conferir, no âmbito das respectivas finalidades e competências, tratamento prioritário aos assuntos relativos às pessoas portadoras de deficiências, visando assegurar a estas a melhoria de sua condição sócio-econômica e a efetiva integração social (Decreto no 11.107/1988).

A Lei Orgânica do DF (LODF), de 1993, assegurou direitos para pessoas com deficiências em diversas áreas: acessibilidade (art. 262; art. 274 e art. 339); assistência social (art. 191, art. 218 e art. 219); educação (art. 229 e art. 232); esporte e lazer (art. 254); saúde (art. 16, art. 207 e art. 208); trabalho e emprego (art. 19 VII). Ademais, prevê que:

Art. 2으...]

Parágrafo único. Ninguém será discriminado ou prejudicado em razão em razão de nascimento, idade, etnia, raça, cor, sexo, estado civil, trabalho rural ou urbano, religião, convicções políticas ou filosóficas, orientação sexual, deficiência física, imunológica, sensorial ou mental, por ter cumprido pena, nem por qualquer peculiaridade ou condição, observada a Constituição Federal (grifos meus).

Os direitos das pessoas com deficiência no DF foram regulamentados nos anos seguintes. Na pesquisa documental foram identificadas 383 leis e atos normativos publicados entre 1981 e 2017, distribuídos da seguinte forma: 
Tabela 1 - Distribuição das leis e atos normativos analisados, segundo o tipo - período 19812017.

\begin{tabular}{l|c}
\hline \multicolumn{1}{c|}{ Tipo } & Quantidade \\
\hline Decreto & 110 \\
Emenda à Lei Orgânica do DF & 4 \\
Instrução, Instrução Normativa e/ou Instrução de Serviço & 9 \\
Lei Distrital & 154 \\
Lei Complementar & 3 \\
Ordem de Serviço & 10 \\
Portaria e/ou Portaria Conjunta & 73 \\
Resolução e/ou Resolução Normativa & 20 \\
\hline Total & 383 \\
\hline
\end{tabular}

Fonte: Da pesquisa "Entre o direito e a filantropia: a proteção social para pessoas com deficiência no Distrito Federal" (2018).

A partir da análise é possível identificar as prioridades elencadas pelos poderes Legislativo e Executivo na área da deficiência ao longo dos anos. Observa-se que transporte concentrou aproximadamente 70\% das legislações elaboradas no período de 1981 a 1990, com 10 ocorrências. A mesma temática continuou com grande quantitativo (26) de leis e atos normativos de 1991 a 2000, seguido pelo tema acessibilidade, com 17 instrumentos legais. Ainda nestes anos a área de trabalho e emprego recebeu suas primeiras regulamentações, em total de nove. Educação e cultura, saúde, habitação e assistência social também começam a ser reconhecidas como direitos no marco legal, mesmo que de maneira incipiente.

Entre 2001 e 2010, a acessibilidade torna-se a temática com mais produções legais e normativas, totalizando $31,6 \%$ do total do período. Foram criadas dez leis e atos sobre participação social, com destaque para as regulamentações sobre o Conselho de Defesa dos Direitos da Pessoa com Deficiência do Distrito Federal (CODDEDE-DF)² e a realização da I e da II Conferência Distrital da Pessoa com Deficiência, respectivamente, em 2006 e 2008. Também se expandem normas nas áreas de assistência social, 12; educação e cultura, 12; habitação, 9; trabalho e emprego, 8; e saúde, 7.

\footnotetext{
${ }^{2}$ Conselho paritário e com caráter deliberativo no campo dos direitos das pessoas com deficiência formado por representantes do governo e da sociedade civil. O CODDEDE-DF foi previsto na Lei Orgânica do DF. Sua primeira regulamentação ocorreu em 1999, por meio do Decreto $n^{\circ} 20.688 / 1999$, alterado posteriormente.
} 
Nos anos mais recentes, de 2011 a 2017, há o crescimento dos marcos legais e normativos de forma geral, com o total de 167 registros. Educação é a área com maior quantitativo, 34. Em segundo lugar está a acessibilidade com 32 ocorrências. Ganha destaque a área de esporte e lazer que, sob influência da realização da Copa do Mundo no Brasil em 2014 e das Olimpíadas do Rio de Janeiro em 2016, teve nove citações.

Há, portanto, um amplo aparato legal e normativo, que abrange diferentes temáticas e áreas no campo da proteção social. A maioria trata de questões relativas à acessibilidade, transporte público e educação com, respectivamente, 91, 62 e 50 ocorrências. É importante considerar que do total, 300 encontram-se sem revogação expressa, sete foram consideradas inconstitucionais ${ }^{3}, 46$ foram alteradas e 30 revogadas. A Tabela 2 mostra o quantitativo de leis e atos normativos sem revogação expressa por tema.

Tabela 2 - Distribuição das leis e atos normativos sem revogação expressa analisados, segundo o tema - período 1981-2017.

\begin{tabular}{l|c}
\hline \multicolumn{1}{c|}{ Tema } & Quantitativo \\
\hline Acessibilidade & 79 \\
Assistência Social & 15 \\
Educação e cultura & 41 \\
Esporte e lazer & 11 \\
Gestão pública & 5 \\
Habitação & 12 \\
Outros & 37 \\
Participação social & 20 \\
Saúde & 19 \\
Trabalho e emprego & 16 \\
Transporte & 45 \\
Total & 300 \\
\hline
\end{tabular}

\footnotetext{
${ }^{3}$ Relatório publicado pelo Observatório Social de Brasília (2017) chama atenção para a grande quantidade de leis aprovadas pela Câmara Legislativa do Distrito Federal (CLDF) que posteriormente foram julgadas inconstitucionais por desvios formais e materiais pelo Supremo Tribunal Federal e o Tribunal de Justiça do Distrito Federal e Territórios. "Uma avaliação possível é a de que os parlamentares possuem conhecimento prévio da inconstitucionalidade das leis em produção, porém aprovam-nas apenas para agradar parte de seu eleitorado. Seria um caso de engodo eleitoral, pois enquanto o eleitorado espera que a legislação produzirá efeitos, o parlamento tem consciência de que a norma será invalidada" (OBSERVATÓRIO SOCIAL BRASÍLIA, 2017, p. 6).
} 
Fonte: Da pesquisa "Entre o direito e a filantropia: a proteção social para pessoas com deficiência no Distrito Federal" (2018).

Para além do aspecto quantitativo das leis, é importante analisar sua dimensão qualitativa, isto é, o conteúdo presente nelas em direção à ampliação de direitos. Percebe-se que, por vezes, as leis e normas publicadas são repetitivas, tratando de assuntos pontuais e não buscando a construção de uma política pública ampla para as pessoas com deficiência. Um caso é a Lei no 2.776/2001, segundo a qual: “Fica determinada a construção de rampa de acesso, para portadores de necessidades especiais, no Setor de Diversão Sul - Bloco "A" N. 41 - 2o Subsolo, na Região Administrativa do Plano Piloto - RA I". Nesse caso, privilegiou-se a elaboração de uma lei que restringe a garantia da acessibilidade a uma rampa de acesso em um local determinado ao invés de abranger a acessibilidade em todas as administrações regionais do DF. A existência de múltiplas leis contribui ainda para tornar o cenário confuso e dificultar a sua efetivação. Como exemplos, podemos citar as leis $n^{\text {os }} 5.383 / 2014$ e $5.384 / 2014$, que foram publicadas na mesma data e com o mesmo assunto, tornando obrigatória "a disponibilização de cadeiras adaptadas em estabelecimentos de ensino e dá outras providências".

Somente no final dos anos 2000 foram criadas leis mais gerais e que buscaram articular a proteção social das pessoas com deficiência para além de políticas específicas. A primeira refere-se à Lei no 3.939/2007, de autoria do Deputado Wilson Lima ${ }^{4}$, que elaborou um quadro mais amplo de ações ao instituir o Estatuto do Portador de Necessidades Especiais no Distrito Federal. Segundo o art. 1ํㅡ, este Estatuto é "destinado a assegurar a integração social e o pleno exercício dos direitos individuais e coletivos das pessoas acometidas por limitações físico-motoras, mentais, visuais, auditivas ou múltiplas que as tornem hipossuficientes para a regular inserção social" (grifos meus). Ademais, apresenta:

Art. 1 [...] $\S$ 10 Para efeitos desta Lei, compreendem-se por portador de necessidades especiais o transplantado e o portador de deficiência de que tratam a Constituição Federal e a Lei Orgânica do Distrito Federal; e por pessoa com deficiência aquela de que trata o art. 1이 da Convenção sobre os Direitos das Pessoas com Deficiência, assinada pelos Estados Parte e 30 de março de 2007, segundo o qual

\footnotetext{
${ }^{4}$ De acordo com a pesquisa documental Wilson Lima foi autor de apenas duas leis que tratam de direitos para pessoas com deficiência: Lei no 2.810/ 2001, que dá tratamento preferencial a idosos, gestantes, deficientes físicos e portadores de necessidades especiais nos locais que menciona, no Distrito Federal, DF; e a Lei no 3.939/2007, que institui o Estatuto do Portador de Necessidades Especiais e dá outras providências.
} 
pessoas com deficiência são aquelas que têm impedimentos de longo prazo de natureza física, mental, intelectual ou sensorial, os quais, em interação com diversas barreiras, podem obstruir sua participação plena e efetiva na sociedade em igualdade de condições com as demais pessoas. (grifos meus)

Apesar de mencionar a definição de pessoa com deficiência proposta pela Convenção Internacional dos Direitos das Pessoas com Deficiência (CDPD) ${ }^{5}$, percebe-se a falta de clareza conceitual sobre o público a quem essa legislação se destina, com a manutenção dos termos portador de necessidades especiais e portador de deficiência e a concepção que os reconhece como incapazes, nos termos de "hipossuficientes para a regular inserção social". Não é tratado seu protagonismo e autonomia, e tampouco considerada a construção social da deficiência. Ao contrário, se reforça o seu modelo individual a partir da ideia de limitação. Assim, é atribuída à pessoa com deficiência a responsabilidade por sua inserção na sociedade.

Na supracitada lei está clara a orientação biomédica na definição de deficiência ao se estabelecer que "Art. 2 ㅇ Os diversos graus e peculiaridades que caracterizam a condição de portador de necessidades especiais serão definidos no regulamento desta Lei, baseados em definições técnico-científicas, devendo-se considerar, sempre que possível, os padrões internacionais" e que as ajudas técnicas "Art. 13 [...] permitem compensar uma ou mais limitações funcionais motoras, sensoriais ou mentais da pessoa portadora de necessidades especiais, com o objetivo de permitir-Ihe superar as barreiras de comunicação e da mobilidade e de possibilitar sua plena inclusão social” (grifos meus).

Na mesma lei são tratadas questões relativas ao direito à vida e à saúde; ao acesso à educação; à habilitação e reabilitação; ao acesso ao trabalho; à cultura, desporto, turismo e lazer; aspectos institucionais; uma política de capacitação de profissionais especializados; e a acessibilidade em prédios públicos. Algumas delas inclusive já haviam sido tratadas de leis anteriores. Segundo o Estatuto:

Art. 40 É dever do Estado, da sociedade e da família assegurar, às pessoas portadoras de necessidades especiais, a efetivação dos direitos referentes à vida, à saúde, à alimentação, à habitação, à educação, à cultura, ao esporte, ao lazer, à profissionalização, ao trabalho, ao transporte, ao acesso às edificações públicas, à seguridade social, à dignidade, ao respeito, à liberdade e à convivência familiar e comunitária. (Lei $n$ o 3.939 de 2007)

\footnotetext{
${ }^{5}$ A Convenção Internacional das Pessoas com Deficiência e seu protocolo facultativo é o mais recente marco internacional de proteção das pessoas com deficiência. No Brasil, foi incorporado com status constitucional por meio do Decreto no 6.949/2009.
} 
Em diversos pontos da referida lei é abordada a articulação entre poder público e entidades da sociedade civil na garantia de direitos, a exemplo da educação (Art. 21, III; Art. 24, §1ำ), por meio das chamadas instituições especializadas; e da habilitação e reabilitação profissional (Art. 34, §1ㅇ; §7ㅇ; §8으) com as entidades beneficentes de assistência social. Cabe destacar que, segundo o art. 50, a execução das políticas públicas para pessoas com deficiência pode ocorrer com o apoio de organizações não-governamentais por meio de convênio, o que levanta o debate sobre a responsabilidade pública sobre a oferta de serviços de proteção social.

Em 2009, foi instituída a Política Distrital para Integração da Pessoa com Deficiência, Lei no 4.317/2009, de autoria do Deputado Benício Tavares ${ }^{6}$. Trata-se de uma lei que "compreende o conjunto de orientações normativas que objetivam assegurar o pleno exercício dos direitos individuais e sociais das pessoas com deficiência" e consolida direitos em diversas áreas como educação, saúde, habitação, transporte e acesso à justiça, ampliando o escopo em relação ao Estatuto anterior. Assim, tem-se uma direção mais sólida em relação à forma como será organizada e executada a proteção social para pessoas com deficiência no DF. Dentre os direitos estabelecidos na legislação estão: direito à vida; à saúde e à habitação; à educação; ao trabalho; à cultura, ao desporto, ao turismo e ao lazer; ao transporte; à acessibilidade; e à informação e à comunicação.

A lei apresenta os termos deficiência, deficiência permanente e incapacidade do mesmo modo que posto no Decreto no 3.298/1999. Embora não cite a CDPD, afirma no art. $5^{\circ}, \S 1^{\circ}$ que "Caracteriza-se também como deficiência a incapacidade conceituada e tipificada pela Classificação Internacional de Funcionalidade, Incapacidade e Saúde - CIF". A legislação aponta para a possibilidade de compreensão da deficiência a partir do modelo biopsicossocial, embora apresente contradições com definições médicas de deficiência.

Uma inovação desta lei refere-se a proposta de "política de atendimento à pessoa com deficiência", a ser implementada por meio de um conjunto articulado de ações do poder público e orientado por princípios como elaboração de políticas sociais básicas, respeito à pessoa com deficiência por meio de priorização de atendimento e igualdade de

\footnotetext{
${ }^{6}$ Benício Tavares é pessoa com deficiência física e usuário de cadeira de rodas. Foi fundador da Associação de Deficientes Físicos de Brasília (ADFB), considerada a primeira associação de pessoas com deficiência do DF (LANNA JÚNIOR, 2010). Com histórico de participação no movimento social das pessoas com deficiência desde os anos 1980, ingressou na política com grande apoio desse segmento. Foi o deputado distrital com maior produção legislativa na temática deficiência, sendo a maioria na área de acessibilidade. Na pesquisa documental foram identificadas 30 leis de sua autoria.
} 
oportunidades, inserção da pessoa com deficiência em todas as iniciativas e programas governamentais, proteção jurídico-social por meio de entidades de defesa de direitos, entre outros.

A terceira proposta de articulação entre as políticas ocorreu em março de 2013, quando o DF aderiu ao Plano Nacional dos Direitos da Pessoa com Deficiência - Viver sem Limite, elaborando o Plano Distrital de Políticas Públicas para Pessoas com Deficiência. Lançado por meio do Decreto № 7.612/2011, o objetivo era “qualificar as políticas públicas de inclusão, buscando garantir a integração de programas e ações que proporcionem o exercício pleno e equitativo dos direitos das pessoas com deficiência" (GDF, 2013, p. 7). As ações foram coordenadas de forma intersetorial, totalizando 35 projetos, sendo oito na área de educação, oito na saúde, 12 na área de inclusão social e sete em acessibilidade.

\section{As contradições das legislações e a efetivação de direitos}

A grande quantidade de legislações foi questionada pelos entrevistados da pesquisa, assim como o compromisso dos governantes na sua efetivação:

\footnotetext{
"Olha, as legislações até que são boas, mas tem que ser revisada muita lei (sic) que não fazem nada, que são criadas, que são ótimas, mas que na prática não funcionam mesmo. Então, assim, deveria ter uma parte mais no governo que faz com que essas leis funcionem. (sic)" (Entrevistada $4^{7}$ - informação verbal $\left.{ }^{8}\right)$;

"Olha, a legislação, assim... eu acredito que se houvesse aplicabilidade das leis que já existem 'tava ótimo (sic). A grande questão é que não há aplicabilidade. [...] Então, a questão da legislação é que existe um excesso de texto, sendo que você, dentro de poucas leis, você garante o direito da maioria das pessoas, né. (sic)" (Entrevistada $24^{9}$ - informação verbal);

"Tá tudo lindo e maravilhoso no papel, mas pra colocar em prática tem uma grande dificuldade, né(sic)." (Entrevistada $16^{10}$ - informação verbal).
}

\footnotetext{
${ }^{7}$ Entrevista concedida à pesquisadora em 18 de janeiro de 2017.

${ }^{8}$ Todas as citações oriundas de transcrições das entrevistas verbais não-publicadas estão apresentadas aqui na sua integralidade e literalidade. Os trechos passaram pelos ajustes estritamente necessários, estão sempre indicados como "informação verbal", escritos com fonte em itálico, e identificados em nota de rodapé. Este é o procedimento consoante com o disposto nas normas técnicas NBR 6023 e NBR 10520, a saber: "quando se tratar de dados obtidos por informação verbal (palestras, debates, comunicações, etc.), indicar, entre parênteses, a expressão informação verbal, mencionando-se os dados disponíveis, em nota de rodapé" (2002, p. 02). [Nota do Revisor]

${ }^{9}$ Entrevista concedida à pesquisadora em 28 de março de 2017.

${ }^{10}$ Entrevista concedida à pesquisadora em 18 de março de 2017.
} 
Observa-se, nos termos de Guerra (2009, p.38), o "fetiche do mero reconhecimento dos direitos" apartado dos meios para a sua efetivação. Isso significa, segundo uma entrevistada, que na maioria das vezes são feitas apenas "políticas de alívio", restritas ao campo da retórica e que não trazem mudanças para as práticas políticas. Assim, a lei torna-se a expressão de anseios e intenções, mas sem obrigações e responsabilidades concretas por parte dos governantes:

"Eu ouvi um professor usando a expressão que alguns governos eles fazem (sic) políticas de alívio que é, por exemplo, o lançamento de uma norma ou de uma política, né, (sic) para poder atender uma expectativa de um segmento populacional sem que efetivamente se adotem novas medidas." (Entrevistada $5^{11}$, informação verbal, grifos meus).

A partir da análise das entrevistas foram identificados três efeitos políticos para explicar a precariedade nas políticas de proteção social para pessoas com deficiência no DF frente os avanços nas garantias legais: falta de vontade política; descontinuidade das ações; e falta de recursos.

Por vontade política entendemos o comprometimento e o empenho do governo em implementar determinada política, assim como oferecer suporte operacional e político para que ela seja efetivada (OLIVEIRA, 2015). A vontade política não é uma variável independente. Ao contrário, está associada a fatores culturais e políticos que compõem a força política entre os atores (NEVES, 2008).

É preciso considerar que a lei, enquanto um direito, é inseparável da presença de uma autoridade que a garanta (GUEIROS, 1991). Tem-se aí uma relação direta com a construção de uma falta de vontade política que se manifesta pelo não compromisso com a efetivação de ações em determinada área apesar do reconhecimento de sua importância e legitimidade. Soma-se a isto, o fato de que historicamente as pessoas com deficiência não foram reconhecidas como cidadãs, mas sim necessitadas, dependentes de concessões e favores (CABRAL FILHO, FERREIRA, 2013; MAIOR, 1997; FIGUEIRA, 2008). A principal expressão dessa falta de vontade política presente nas entrevistas é não tratar as demandas das pessoas com deficiência como prioritárias:

Eu acho que ele [o governo] vê o deficiente como não prioridade, entendeu. (sic)" (Entrevistado $11^{12}$, informação verbal);

\footnotetext{
${ }^{11}$ Entrevista concedida à pesquisadora em 20 de janeiro de 2017.

${ }^{12}$ Entrevista concedida à pesquisadora em 10 de março de 2017.
} 
Eu acredito que não priorizam de forma nenhuma porque eles acham que não tem necessidade, né, da inclusão. (sic)" (Entrevistada $17^{13}$, informação verbal).

Que recurso, dinheiro, a gente sabe que existe. Falta boa vontade, né. Às vezes falta boa vontade mesmo de fazer, né. Vamos fazer uma rampa? Vamos fazer uma acessibilidade melhor, né? Até pro cego, pro surdo, né, pra outras deficiências também. (sic) [...] Tem muita coisa para mudar, muita coisa. Não é pouca não. Mas eu acho que o principal é perceber isso e se voltar a esse público, sabe, a vontade de fazer por estes. (sic) (Entrevistada $18^{14}$, informação verbal).

Assim, cria-se um cenário que permite ao governante escolher se cumprirá ou não as leis, e sua efetivação implica em um esforço e um comprometimento pessoal em detrimento do reconhecimento de um direito conquistado pela população.

O efeito político do não reconhecimento da cidadania é o atendimento de necessidades individuais a partir de uma relação personalista com o governante, o que perpetua práticas assistencialistas no campo da proteção social (NEVES, 2008). Assim, aqueles políticos que mostram pequenos comprometimentos e efetuam ações pontuais acabam por tornarem-se referência de atenção às pessoas com deficiência. A Entrevistada 15, por exemplo, expressou admiração e gratidão por um governante do DF que se mostrou solidário com questões de acessibilidade: "Assim, eu não vou fazer apologia à governo, mas teve um dos governadores aí (sic) que ele sentou numa cadeira de rodas, ele sentou numa cadeira de rodas e aí ele saiu, né, vendo lá como eram os locais, pontos estratégicos (sic)." (Entrevistada 15, informação verbal).

Nesse sentido, o indicador "vontade política" também esteve presente nas reflexões dos entrevistados sobre as relações tecidas com o Poder Legislativo. Tendo em vista uma série de precariedades nas políticas sociais para pessoas com deficiência no DF, recorrer a deputados distritais surge como uma alternativa para que as demandas pessoais sejam atendidas (BEZERRA, 1999; NEVES, 2008). A burocratização no acesso aos serviços públicos também foi mencionada nas entrevistas como outro impeditivo no processo de garantia de direitos, que torna as relações orientadas por sentimentos de gratidão e apoio, e não pela construção da cidadania. Segundo Bahia (2003), a oportunidade dos governantes exercerem a discricionariedade na implementação de políticas públicas e legislações aumenta o potencial de relações clientelistas. Isto é, o Estado opera em diversas vezes “criando dificuldades para

\footnotetext{
${ }^{13}$ Entrevista concedida à pesquisadora em 21 de março de 2017.

${ }^{14}$ Entrevista concedida à pesquisadora em 24 de março de 2017.
} 
vender facilidades" (SPOSATI, 2008, p. 21). Demo (1991) argumenta na mesma direção afirmando que essa é uma forma típica de abuso do poder político, pois orienta-se pela oferta de vantagens e concentração de privilégios.

A participação política e a mobilização das pessoas com deficiência no espaço público são algumas das respostas frente à falta de vontade política. Ou seja, são ações que pressionam o governo na garantia de direitos, reconhecimento de cidadania e efetivação da proteção social. Nos termos de Nogueira (2011, p. 137),

por intermédio da participação política, indivíduos e grupos interferem para fazer com que diferenças e interesses se explicitem num terreno comum organizado por leis e instituições, bem como para fazer com que o poder se democratize e seja compartilhado. É essa participação, em suma, que consolida, protege e dinamiza a cidadania e todos os variados direitos humanos.

Os protagonistas centrais desse processo são os cidadãos. É a cidadania organizada que coloca o cidadão como figura central da vida democrática (DEMO, 1991).

O segundo efeito político identificado nas entrevistas como explicação para a não efetivação das leis pelo poder público decorre da descontinuidade das ações, principalmente em virtude de mudanças de gestão, trocas de alianças políticas e alterações no desenho institucional. Essa descontinuidade também é um dos traços da cultura política do DF, já que os programas e as ações de governo são percebidos como resultado da ação pessoal do político que o conduziu. Os depoimentos abaixo corroboram essa argumentação:

\begin{abstract}
Infelizmente, a cultura brasileira não favorece essas ações, esses projetos, essas associações, nada disso. Por que? Porque uma pessoa, um governo, um partido inicia um processo e o seguinte, pode até ser do mesmo partido, mas como muda a cabeça pensante, essa cabeça nova não quer continuar no projeto que o outro iniciou e que poderia estar indo muito bem, como tanto faz, que ele não vai apoiar. Eles não têm interesse em dar continuidade às coisas que os outros fizeram. Infelizmente é isso que aconteceu aqui. (Entrevistado $26^{15}$, informação verbal).

Outra coisa é que a gente vê o entra e sai no governo. Tem gente que entra com vontade, com ideia bacana, mas muda a pessoa, vai embora, muda o governo, muda a gestão, e o projeto para. Não há um interesse em dar continuidade ao que já foi iniciado e tá dando certo (sic). A gente tem ideia de que é por esse motivo que não funciona. (Entrevistada $25^{16}$, informação verbal).

Essas mudanças de governo constantes, mudança de secretário e tudo mais. A gente tem que começar tudo de novo. Aí começa, volta todo o diálogo, explica tudo de novo. Então, tem hora que cansa. Mas não dá pra cansar, né, tem que correr atrás.
\end{abstract}

\footnotetext{
${ }^{15}$ Entrevista concedida à pesquisadora em 29 de março de 217.

${ }^{16}$ Entrevista concedida à pesquisadora em 07 de abril de 2017.
} 
A gente vê muito uma política passageira, né. A gente verifica que não tem uma coisa permanente. (Entrevistada $36^{17}$, informação verbal).

Isso significa a prevalência do interesse individual do governante em relação à garantia de direitos e à qualidade do serviço prestado. De acordo com os entrevistados, o que existem são políticas de governo e não políticas de Estado. Ou seja, ações com um tempo limitado para durar, em geral um mandato, e que buscam garantir votos para a eleição seguinte:

"Porque não é uma política de Estado, é uma política de governo simplesmente. Eles querem que você chegue lá com uma solução e essa solução tenha um impacto social que dê voto, né. (sic)" (Entrevistado $9^{18}$ - informação verbal);

"A questão política ela é bem cruel porque a política ela não tem esse olhar mesmo (sic). Você não tem um político que ele quer olhar pra aquela pessoa. Ele quer saber de números, se vão dar votos." (Entrevistada 24- informação verbal)

A defesa dos direitos das pessoas com deficiência fica, então, restrita ao campo da retórica. As entrevistas evidenciam o hiato entre um discurso que defende o público das pessoas com deficiência e a falta de ações concretas:

Ninguém é contra o idoso. Ninguém é contra a pessoa com deficiência, né (sic). [...] Mas apesar de ninguém ser contra pautas como essas, a gente não vê uma atuação muito presente, né (sic), muito participativa. (Entrevistada 5 - informação verbal);

Apesar de ser uma causa justa, uma causa que todo mundo apoia, mas quando chega realmente na hora de batalhar, de tentar conseguir, já é mais difícil, né (sic). A pessoa, às vezes se compromete com a gente, mas chega lá na hora: 'Ah, não. Não é bem assim'. (Entrevistada 36 - informação verbal).

O desenho institucional torna-se um elemento fundamental a ser considerado. Não se trata apenas do formato como ocorre a gestão pública, mas também de regras, critérios, metodologias e espaços que promovem tais ações entre cidadãos e seus representantes (OLIVEIRA, 2015; WAMPLER, 2003). Assim, estão em jogo indicações de pessoas para assumirem cargos de chefia e direção e alianças político-partidárias. Em suma, um conjunto de práticas políticas por vezes orientadas por interesses individuais, assistencialistas e clientelistas impeditivos de uma cultura democrática.

\footnotetext{
${ }^{17}$ Entrevista concedida à pesquisadora em 12 de abril de 2017.

${ }^{18}$ Entrevista concedida à pesquisadora em 24 de janeiro de 2017.
} 
Desde a criação da CORDE/DF, em 1988, o órgão gestor das políticas para pessoas com deficiência teve seu formato alterado, deixando de ser vinculado à governadoria e passando para secretarias responsáveis pelas temáticas de assistência social e direitos humanos em governos posteriores. Nesse sentido, vários entrevistados destacaram que a atuação do Governo do Distrito Federal (GDF) está mais preocupada com uma disputa políticopartidária, especialmente no que se refere à indicação de cargos, do que com o compromisso com a garantia de direitos: "Porque ainda tem pessoas que tão utilizando esses cargos não pra defender um programa social, mas pra usar como cargo pessoal, pra ter uma fonte financeira." (Entrevistado $19^{19}$ - informação verbal).

A importância do desenho institucional na condução da política pública é desmistificada quando comparada com as suas práticas cotidianas. Isso porque a falta de transparência na administração pública e a existência de práticas personalistas acabam por colocar em xeque a garantia de direitos. O desafio posto refere-se à democratização da gestão (SOUZA FILHO, 2013; SOUZA FILHO, GURGEL, 2016; NOGUEIRA, 2011; NEVES, 2008).

Por fim, outra explicação dada pelos entrevistados para que as leis não se tornem realidade na vida das pessoas com deficiência é a falta de recursos. Esta é uma declaração controversa, uma vez que os limites orçamentários e financeiros são de praxe e estão presentes nos discursos de todos os governos, especialmente alinhados à austeridade fiscal que impacta as políticas sociais. Entretanto, no atual cenário, narrativas acerca da crise econômica estão ainda mais recorrentes na mídia e têm sido utilizadas para justificar cortes de verbas e promover enxugamento de serviços públicos.

De acordo com as falas dos entrevistados, a ênfase dada à falta de recursos por parte do GDF retira a noção de direitos das pessoas com deficiência e as resume a um gasto. $O$ debate político em torno de justiça social, igualdade e cidadania passa a ser técnico, amparado no orçamento e em metas econômicas:

Realmente o governo não vê como prioridade a área da deficiência. Ele tá vendo como um gasto, né, e não como um direito. (Entrevistada 17 - informação verbal);

Eu acho que ainda é um pouco considerado, assim, fundo perdido. Só um gasto, né. E mesmo que fosse também, né, é um dever do Estado garantir. (sic) (Entrevistada $29^{20}$ - informação verbal);

Quando a gente chega com uma solução que envolve gasto, eles não querem. [...] 'Não, eu não quero ouvir isso. Eu quero alguma coisa mágica, assim, aonde eu solto

\footnotetext{
${ }^{19}$ Entrevista concedida à pesquisadora em 27 de março de 2017.

${ }^{20}$ Entrevista concedida à pesquisadora em 01 de abril de 2017.
} 
na mídia, amanhã vai dar uma repercussão muito grande, e eu não tenho que gastar nada com isso.' (sic) (Entrevistado 9 - informação verbal).

Nesse sentido, a noção de cidadão é substituída pela de consumidor de serviços públicos, que devem contribuir para a estabilidade financeira do Estado (SOUZA FILHO; GURGEL, 2016). Conforme explica outro entrevistado: "O que eu tenho de ganho com pessoas com deficiência? Nada. [...] O que essas pessoas com deficiência, para o Estado, têm de retorno? Nenhum. Nenhum." (Entrevistado $23^{21}$ - informação verbal).

Vários entrevistados, por outro lado, questionam o discurso da falta de recursos e afirmam a existência de um direcionamento político que se opõe ao atendimento das necessidades sociais das pessoas com deficiência. Assim, vontade política e falta de recurso tornam-se expressões da escolha de prioridades a serem atendidas por meio de políticas públicas:

Eu ouvi também pessoas falando que: "Ah, a gente 'tá sem dinheiro até 'pra professor da escola (sic). Então, a gente não tem como tirar dinheiro pra isso". E eu ouvi também pessoas falando que isso é um projeto de baixo custo que eles poderiam arcar. Então, eu fico super na dúvida. Eu fico assim: "Cara, será que eles têm? Será que eles não têm? Será que é má vontade?" Eu não sei te responder. (Entrevistada $37^{22}$ - informação verbal).

Eu acho que depende mais do governo local. Eles alegam muitas vezes não ter verbas, não tem recurso para criar um abrigo, criar uma instituição (sic). É isso. Eles alegam não ter recurso. Eles ficam aguardando a demanda aumentar para poder criar um serviço. Eu vejo que falta vontade política. A gente não sabe se é recurso financeiro ou é falta de gestão. (Entrevistada 25 - informação verbal).

Neste contexto de falta de transparência sobre os gastos do governo, a limitação de recursos financeiros disponíveis torna-se uma justificativa para a opção por não executar ações. Mais do que existir ou não recursos, é fundamental compreender o direcionamento político e o comprometimento governamental das ações pela garantia ou não de direitos sociais.

Este complexo cenário da proteção social para pessoas com deficiência no DF levou alguns entrevistados a afirmarem que há uma "ausência de políticas públicas". Entende-se que essa afirmação não significa necessariamente que elas não sejam ofertadas, mas sim, que elas não contemplam as especificidades das suas necessidades e nem garantem direitos. Por

\footnotetext{
${ }^{21}$ Entrevista concedida à pesquisadora em 28 de março de 2017.

22 Entrevista concedida à pesquisadora em 19 de abril de 2017.
} 
não garantir direitos, o governo torna-se uma barreira para a inclusão, segundo um participante da pesquisa:

\begin{abstract}
O governo é a barreira da inclusão para os surdos, entendeu. E não só da inclusão para os surdos, para o cadeirante... O governo é a grande barreira, entendeu. Olha, falar isso é muito complicado porque o governo tinha que ser o promotor das políticas. (Entrevistado $8^{23}$ - informação verbal).
\end{abstract}

\title{
Considerações finais
}

É possível afirmar que a trajetória da proteção social para pessoas com deficiência no DF passou por três momentos. No primeiro, nas décadas de 1980 e 1990, a proteção social começou a ser estruturada para as pessoas com deficiência no DF a partir de leis isoladas nas diferentes políticas públicas, com maior ênfase a pessoas com deficiência física e garantias nas áreas de acessibilidade e transporte.

No momento seguinte, a partir dos anos 2000 , se busca uma proteção social em sentido ampliado e orientada pela articulação e integração entre as ações das diversas áreas, marcado pelas Leis 3.939/2007 e 4.317/2009. Percebe-se que a definição de deficiência permanece orientada pelo modelo biomédico, o que entendemos trazer impactos para a perspectiva de garantia de direitos e justiça social.

Identifica-se, portanto, uma dissonância entre os debates sistematizados na Convenção Internacional dos Direitos das Pessoas com Deficiência e, posteriormente na Lei Brasileira de Inclusão, e o marco legal distrital, especialmente quanto à definição de quem são as pessoas com deficiência. Se no âmbito internacional já se materializa a definição de deficiência a partir da restrição de participação, no DF continuam sendo publicadas leis que dispõe estritamente de dimensão biomédica. As implicações são diretas para a concretização de direitos para esse público. Se por um lado um modelo preconiza a responsabilidade do Estado com a proteção social, no âmbito da igualdade e da justiça social, por outro perpetuase a responsabilidade individual da pessoa com deficiência por sua condição, associada ao trato filantrópico e caritativo com a temática.

O terceiro momento é marcado pelo Plano Viver sem Limites, no qual há uma articulação entre governo federal e distrital e a proposição de ações concretas, inclusive com

\footnotetext{
${ }^{23}$ Entrevista concedida à pesquisadora em 30 de janeiro de 2017.
} 
repasse de recursos orçamentários, em diferentes áreas. Trata-se de buscar a implementação do que já está garantido em leis e normas tanto no Brasil quanto no DF. Embora ainda exista uma carência de estudos sobre os resultados e os impactos deste Plano, cabe destacar que sua proposta foi orientada pela intersetorialidade e transversalidade nas ações.

Ainda há um longo caminho a ser percorrido na superação do hiato entre as legislações e marcos normativos e a consolidação da proteção social para pessoas com deficiência no DF. Para tanto, é necessária uma mudança na cultura política orientada pelo reconhecimento das pessoas com deficiência enquanto sujeitos de direito. A noção de cidadania identificada a partir dos dados está restrita e estática ao plano institucional de garantias legais individuais, dissociada de uma práxis política. Ou seja, os direitos ficam limitados ao campo formal e normativo, sem referência a questões políticas e éticas nem à responsabilidade pública na sua garantia. Tampouco os serviços são expressão concreta dos direitos de cidadania.

\section{Referências bibliográficas}

BAHIA, Luiz Henrique Nunes. O poder do clientelismo: raízes e fundamentos da troca política. Rio de Janeiro; São Paulo: Renovar, 2003.

BEZERRA, Marcos Otávio. Em nome das "bases": política, favor e dependência pessoal. Rio de Janeiro: Relume Dumará: Núcleo de Antropologia da Política, 1999.

BRASIL. Decreto n 3.298, de 20 de dezembro de 1999. Regulamenta a Lei no 7.853, de 24 de outubro de 1989, dispõe sobre a Política Nacional para a Integração da Pessoa Portadora de Deficiência, consolida as normas de proteção, e dá outras providências. Disponível em: http://www.planalto.gov.br/ccivil_03/decreto/d3298.htm. Acesso em 24 jun. 2016.

Decreto no 7.612, de 17 de novembro de 2011. Institui o Plano Nacional dos Direitos da Pessoa com Deficiência - Plano Viver sem Limite. Disponível em: http://www.planalto.gov.br/ccivil_03/_ato2011-2014/2011/decreto/d7612.htm. Acesso em 2 jul. 2017.

CABRAL FILHO, Adilson Vaz; FERREIRA, Gildete. Movimentos sociais e o protagonismo das pessoas com deficiência. Ser Social, Brasília, v. 15, n. 32, p. 93-116, jan./jul. 2013. Disponível em: http://periodicos.unb.br/index.php/SER_Social/article/viewFile/9599/7136. Acesso em 28 mai. 2016.

CHAUÍ, Marilena. Conformismo e resistência: aspectos da cultura popular no Brasil. 6 ed. São Paulo: Brasiliense, 1994.

DEMO, Pedro. Pobreza política. 3 ed. São Paulo: Cortez, 1991. 
FIGUEIRA, Emilio. Caminhando em silêncio: uma introdução à trajetória das pessoas com deficiência na história do Brasil. 2 ed. São Paulo: Giz Editora, 2008.

GIBSS, Graham. Análise de dados qualitativos. Porto Alegre: Artmed, 2009.

GOVERNO DO DISTRITO FEDERAL - GDF. Decreto $\mathrm{n}^{\circ}$ 5.839, de 16 de março de 1981. Institui Comissão, no Distrito Federal, do Ano Internacional das Pessoas Deficientes. Disponível em: http://www.sinj.df.gov.br/sinj/Norma/7822/Decreto_5839_16_03_1981.html. Acesso em 12 out. 2017.

Decreto $n^{\circ}$ 11.107, de 18 de maio de 1988. Dispõe sobre as ações da Administração do Distrito Federal relativas às pessoas portadoras de deficiência e dá outras providências. Disponível em: http://www.sinj.df.gov.br/sinj/Norma/16122/Decreto_11107_18_05 _1988.html. Acesso em 12 out. 2017.

Lei Orgânica do Distrito Federal. Disponível em: http://www.sinj.df.gov.br/sinj/Norma/66634/Lei_Org_nica_08_06_1993.html. Acesso em 11 fev. 2018.

Lei no 2.776, de 27 de setembro de 2001. Determina a colocação de rampas de acesso, no local que especifica, para portadores de necessidades especiais. Disponível em: http://www.sinj.df.gov.br/sinj/Norma/50732/Lei_2776_27_09_2001.html. Acesso em 15 out. 2017.

Lei no 3.939, de 2 de janeiro de 2007. Institui o Estatuto do Portador de Necessidades Especiais e dá outras providências. Disponível em: http://www.sinj.df.gov.br/sinj/Norma/54438/Lei_3939_02_01_2007.html. Acesso em 15 out. 2017.

. Lei no 4.317, de 9 de abril de 2009. Institui a Política Distrital para Integração da Pessoa com Deficiência, consolida as normas de proteção e dá outras providências. Disponível em: http://www.sinj.df.gov.br/sinj/Norma/60186/Lei_4317_09_04_2009.html. Acesso em 24 ago. 2017.

. Lei no 5.383, de 12 de agosto de 2014. Torna obrigatória a disponibilização de cadeiras adaptadas em estabelecimentos de ensino e dá outras providências. Disponível em: http://www.sinj.df.gov.br/sinj/Norma/77463/Lei_5383_12_08_2014.html. Acesso em 30 out. 2017.

Lei no 5.384, de 12 de agosto de 2014. Torna obrigatória a disponibilização de cadeiras adaptadas em estabelecimentos de ensino e dá outras providências. Disponível em: http://www.sinj.df.gov.br/sinj/Norma/77468/Lei_5384_12_08_2014.html. Acesso em 30 out. 2017.

Plano Distrital de Políticas Públicas para Pessoas com Deficiência: Viver sem Limites Brasília: GDF, 2013.

. Secretaria de Estado de Ação Social. Portaria no 98, de 12 de abril de 2006. Constitui a Comissão Organizadora, com o objetivo de monitorar e avaliar as deliberações da "I Conferência Distrital de Defesa dos Direitos da Pessoa com Deficiência". Disponível em: 
http://www.buriti.df.gov.br/ftp/diariooficial/2006/04_Abril/DODF\%20074\%2018-042006/Se\%C3\%A7\%C3\%A3o02-\%20074.pdf. Acesso em 22 dez. 2017.

GUEIROS, Maria José Galvão. Serviço Social e Cidadania. Rio de Janeiro: Agir, 1991.

GUERRA, Yolanda. Direitos sociais e sociedade de classes: o discurso do direito a ter direitos. In: FORTI, Valeria; GUERRA, Yolanda (Org.). Ética e direitos: ensaios críticos. Rio de Janeiro: Lumen Juris, 2009.

LANNA JÚNIOR, Mário Cléber Martins (Comp.). História do movimento político das pessoas com deficiência no Brasil. Brasília: Secretaria de Direitos Humanos. Secretaria Nacional de Promoção dos Direitos da Pessoa com Deficiência, 2010.

OLIVEIRA, Priscila Nolasco de. Democracia e participação social: um estudo sobre o Orçamento Participativo no Distrito Federal. 206f. Dissertação (Mestrado em Política Social)Universidade de Brasília, 2015.

NEVES, Angela Vieira. Cultura política e democracia participativa: um estudo sobre o orçamento participativo. Rio de Janeiro: Gramma, 2008.

NOGUEIRA, Marco Aurélio. Um Estado para a sociedade civil: temas éticos e políticos da gestão democrática. 3. ed. São Paulo: Cortez, 2011.

OBSERVATÓRIO SOCIAL BRASÍLIA. Relatório do projeto Produção Legislativa CLDF 2016. Brasília, 2017. Disponível em: http://osbrasilia.org/relatorios/2017-prolegis-analise-deproducao-legislativa/. Acesso em 12 fev. 2020.

SIMÕES, Carlos. Curso de Direito do Serviço Social. 2 ed. rev. e atual. São Paulo: Cortez. 2008.

SOUZA FILHO, Rodrigo de. Gestão pública e democracia: a burocracia em questão. 2 ed. Rio de Janeiro: Lumen Juris, 2013.

; GURGEL, Claudio. Gestão democrática e Serviço Social: princípios e propostas para a intervenção crítica. São Paulo: Cortez, 2016.

SPOSATI, Aldaíza de Oliveira. A assistência social e a trivialização dos padrões de reprodução social. In: SPOSATI, Aldaíza; FALCÃO, Maria do Carmo; TEIXEIRA, Sônia Maria Fleury. Os direitos (dos desassistidos) sociais. 6 ed. São Paulo: Cortez, 2008.

TELLES, Vera da Silva. Sociedade civil e a construção de espaços públicos. In: DAGNINO, Evelina (Org.). Os anos 1990: política e sociedade no Brasil. São Paulo: Brasiliense, 1994.

VIEIRA, Evaldo. Os direitos e a política social. São Paulo: Cortez, 2004.

WAMPLER, Brian. Orçamento Participativo: uma explicação para as amplas variações nos resultados. In: AVRITZER, Leonardo; NAVARRO, Zander (Orgs). A inovação democrática no Brasil: o orçamento participativo. São Paulo: Cortez, 2003.

Recebido em: 06.04.2021

Aceito em: 20.08.2021 